\title{
STUDIES ON STRESS AND STRAIN STATE OF A HIP JOINT ENDOPROSTHESIS
}

\author{
Sticlaru, C.; DAVIDESCU, A.; CRAINIC, N. \& FAUR, C.
}

Abstract: The paper presents a study on a hip joint endoprosthesis. The model for the femur was obtained by CT scanner and Mimics, the endoprosthezis was designed in proEngineer. The paper deals with some stress and strain aspects for hip joint endoprosthesis. These aspects are depicted from a complex finite element analyze in Ansys. This study has two stages: obtaining the 3D model for the bone and endoprosthesis, analysing the model in Ansys - to obtain stress and stree state information. With these information the orthopedist takes the good decision for a proper hip joint endoprosthesis used for a named patient.

Key words: total hip arthroplasty, computational model, hip prosthesis, stress state, strain state of a hip joint
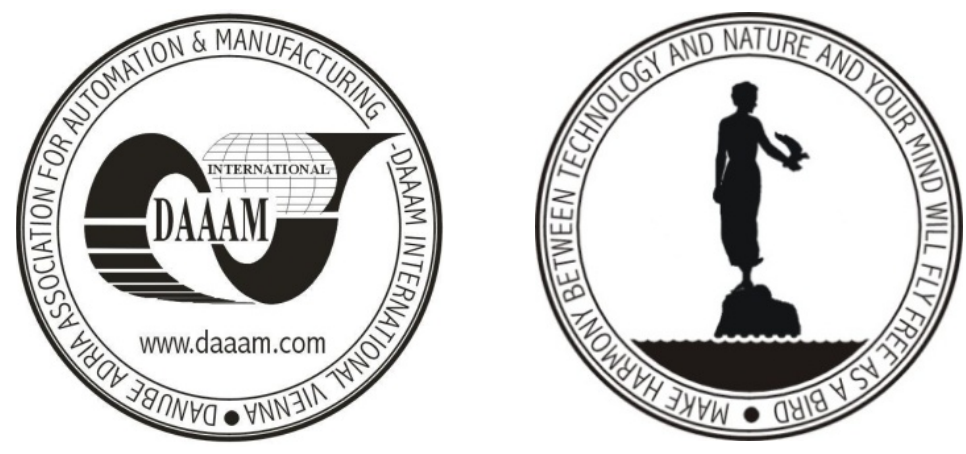

Authors' data: Univ.assist. Prof. Dr. Ing. Sticlaru, C[armen]*; Univ. Prof. Dr. Ing. Davidescu, A[rjana]*; Univ.assist. prof. Dr. Ing. Crainic N[icolae]*; univ. assist. medical doctor Faur, C[osmin]**, *Politehnica University of Timisoara, b-dul Mihai Viteazu nr.1, 300222, Timisoara, Romania, ** University of Medicine and Pharmacology Timisoara, Romania, carmen.sticlaru@mec.upt.ro, arjana.davidescu@mec.upt.ro,ncrainic@gmail.com, faur17@yahoo.co.uk

This Publication has to be referred as: Sticlaru, C[armen]; Davidescu A[rjana]; Crainic N[icolae] \& Faur C[osmin] (2009). Studies on Stress and Strain State of a Hip Joint Endoprosthesis, Chapter 82 in DAAAM International Scientific Book 2009, pp. 853-864, B. Katalinic (Ed.), Published by DAAAM International, ISBN 978-3901509-69-8, ISSN 1726-9687, Vienna, Austria

DOI: 10.2507/daaam.scibook.2009.82 